\title{
Transport and bottom accumulation of fine river sediments under typhoon conditions and associated submarine landslides: case study of the Peinan River, Taiwan
}

\author{
A. A. Osadchiev ${ }^{1}$, K. A. Korotenko ${ }^{1}$, P. O. Zavialov ${ }^{1}$, W.-S. Chiang ${ }^{2}$, and C.-C. Liu ${ }^{2}$ \\ ${ }^{1}$ P. P. Shirshov Oceanology Institute, Moscow, Russia \\ ${ }^{2}$ Tainan Hydraulics Laboratory, National Cheng-Kung University, Tainan, Taiwan
}

Correspondence to: A. A. Osadchiev (osadchiev@ocean.ru)

Received: 2 July 2015 - Published in Nat. Hazards Earth Syst. Sci. Discuss.: 31 August 2015

Revised: 10 November 2015 - Accepted: 11 December 2015 - Published: 18 January 2016

\begin{abstract}
A combination of a three-dimensional Eulerian ocean circulation model (Princeton ocean model, POM) and a Lagrangian particle-tracking model (Surface-Trapped River Plume Evolution, STRiPE) is used to study the fate of fine river sediments discharged by the Peinan River at the southeastern coast of the island of Taiwan. The composite model is verified against in situ measurements and applied to simulate primary sediment deposition under freshet and typhoon discharge conditions of the Peinan River. It is shown that local wind plays a crucial role in sediment transport and settling in the coastal area through its influence on the river plume dynamics and turbulent mixing in the upper layer. Wind forcing conditions generally determine the location of the sediment deposit area, while its final pattern is defined by coastal circulation as modulated by the geometry of the coast and local bathymetry. In the study, region riverborne sediments are deposited to the sea floor, mainly in the shallow shelf areas. A significant portion of discharged fine sediments is moved offshore to the deeper ocean where it is further advected and dispersed by strong coastal circulation, mainly governed by the Kuroshio Current.

The performed numerical experiments showed that sediment accumulation rate under typhoon conditions is about 2 orders of magnitude greater compared to freshet conditions. Based on the simulation results, we identified areas of continental shelf and continental slope adjacent to the Peinan River estuary which exhibit a high risk of formation of submarine landslides during and shortly after the typhoon events.
\end{abstract}

\section{Introduction}

Small rivers transport a significant volume of terrigenous sediment to the ocean on the global scale (Milliman and Syvitski, 1992) and affect short-term and long-term coastal and seabed characteristics (Syvitski and Saito, 2007; Milliman et al., 2007). Particularly, elevated sediment deposits can initiate submarine landslides and subsequent autosuspending turbidity flows, which are frequently observed at certain coastal areas (e.g., Hampton et al., 1996; Lamb and Mohrig, 2009; Carter et al., 2012; Warrick, 2014). One good example is the small mountainous rivers of Taiwan which deliver 180-380 million tonnes of terrigenous constituents annually. This relatively large discharge is associated with peculiar climatic, topographic, lithological, and anthropogenic features of Taiwan (Dadson et al., 2003; Kao et al., 2005, 2008).

The major part of riverine water and sediment is discharged from the island of Taiwan during the monsoon season (June-September) when river and sediment runoff are several orders of magnitude greater compared to the dry season (Warrick and Milliman, 2003; Mirabito et al., 2012). An even more dramatic intensification of the discharge is observed during short-term typhoon events, which were recorded to have occurred 255 times during 1949-2009 (Chang et al., 1993; Liu et al., 2006). On average, 60-80\% sediment load is deposited at the steep eastern and southwestern shelves of the island (Liu et al., 2008), which are characterized by elevated seismic activity. The coaction of rapid accumulation and under-consolidation of sediments with earthquake events, which are potential triggers of submarine land- 
slides, have been the subject of considerable research efforts (e.g., Hsu et al., 2008; Huh et al., 2009; Hale et al., 2012; Carter et al., 2012).

Energetic turbidity flows can erode and transport a huge amount of terrigenous material from shelf areas to the deep sea via submarine canyons (Walsh and Nittrouer, 2009; Meiburg and Kneller, 2010). Taiwan rivers are characterized by high concentrations of total particulate organic carbon (Kao and Liu, 1996; Hilton et al., 2008); therefore, turbidity currents at the Taiwan shelf play an important role in the burial of organic carbon. Also, they have caused a number of destruction events of underwater pipelines, telecommunication cables, and other artificial structures at the continental shelf and continental slope (Carter et al., 2014). In particular, a number of cable breaks in the eastern and southwestern coastal areas of Taiwan happened after the Pingtung earthquake in 2006, which caused serious failures in data transmission for the whole Asian Pacific region (Hsu et al., 2008). Therefore, the identification of coastal areas which can be potentially influenced by gravity flows has significant practical importance.

Turbidity currents at the Taiwan shelf are mainly caused by two different mechanisms, namely, hyperpycnal river discharge and excrescent accumulation of fine sediment, resulting in submarine landslides. The first mechanism which emerges at river estuaries during typhoon events when river sediment concentration exceeds a certain value has been considered in many works (e.g., Dadson et al., 2005; Milliman and Kao, 2005; Milliman et al., 2007). However, much less attention was paid to the second mechanism which also can be induced by elevated sediment load during and shortly after typhoon events. It has a significantly longer preconditioning period and is characterized by distributed potential sources of turbidity flows (Carter et al., 2014).

The present work is focused on the fate of fine sediment discharged by the Peinan River at the northeastern coast of Taiwan and related identification of areas of potential formation of submarine landslides, based on the simulated mass distribution of sediment deposit at the seafloor. Previous studies of river-borne sediment dispersal in coastal areas have demonstrated its high variability caused by the influence of external forcing factors, namely, volume of sediment discharge, sediment concentration in river water, grainsize distribution, coastal flows including tidal circulation, wave forcing, and margin geometry (e.g., Orton and Reading, 1993; Walsh and Nittrouer, 2009). Transport of sediments is determined by the motion of a buoyant river plume on the one hand, and ambient coastal circulation on the other. Many general aspects of sediment delivery to the ocean floor in coastal areas remain unclear (Milliman and Kao, 2005; $\mathrm{Yu}, 2006)$. This justifies the necessity for research focused specifically on the fate of river-borne sediments, in particular, in the area adjacent to the Peinan River estuary.

In this work we use a combination of Lagrangian and Eulerian modeling to reproduce transport and settling of fine terrigenous sediments discharged from the Peinan River. For this purpose, we track these particles as passive tracers of river outflow using a recently developed Lagrangian model called Surface-Trapped River Plume Evolution (STRiPE) applied to the Peinan River plume. After a particle sinks beneath the plume, its movement is governed by coastal circulation simulated by the Princeton ocean model (POM). The combination of the models was applied for the study region and validated against in situ measurements. Then we performed numerical experiments to compare the fate of fine sediment under freshet and typhoon forcing conditions and composed respective maps of mass distribution of sediment deposits at the seafloor. Finally, based on the modeling results and high-resolution bathymetry, we evaluated the probability of the formation of typhoon-induced submarine landslides in the study area.

The article is organized as follows: Sect. 2 provides detailed information about the study region and in situ data, collected during field work in the study region in April 2014, and used for the model validation. Section 3 is focused on the general description and implementation of the joint model. The results of numerical simulations of sediment transport under freshet and typhoon forcing conditions are described in Sect. 4. Discussion of model results and identification of zones of potential submarine landslides in the study area is given in Sect. 5, followed by the summary and the conclusions in Sect. 6.

\section{Study area}

The study region is located on the southeastern coast of Taiwan, in the area adjacent to the Peinan River estuary (Fig. 1). The oceanographic conditions off the eastern coast of Taiwan are mainly governed by the Kuroshio Current, as well as tides, winds, and river discharge.

\subsection{The Kuroshio Current}

The Kuroshio Current (KC) originates from the northern branch of the North Equatorial Current (NEC). After the bifurcating of NEC near the Philippine archipelago, KC passes through the Luzon Strait and flows northward along the eastern coast of Taiwan. On average, $\mathrm{KC}$ spans from the eastern coast of Taiwan to $100-150 \mathrm{~km}$ offshore and its depth reaches 800-1000 m (Liang et al., 2003; Hsin et al., 2008). According to in situ data collected by numerous hydrographic surveys and current meter observations, the northward transport of $\mathrm{KC}$ along the eastern coast of Taiwan is estimated to be about $30 \mathrm{~Sv}$ (Hsin et al., 2008). However, KC has strong variability, ranging from synoptic to interannual; in particular at the annual scale, it strengthens in summer and weakens in winter (Gilson and Roemmich, 2002). However, the position of $\mathrm{KC}$ along the coast changes nonuniformly; particularly in 


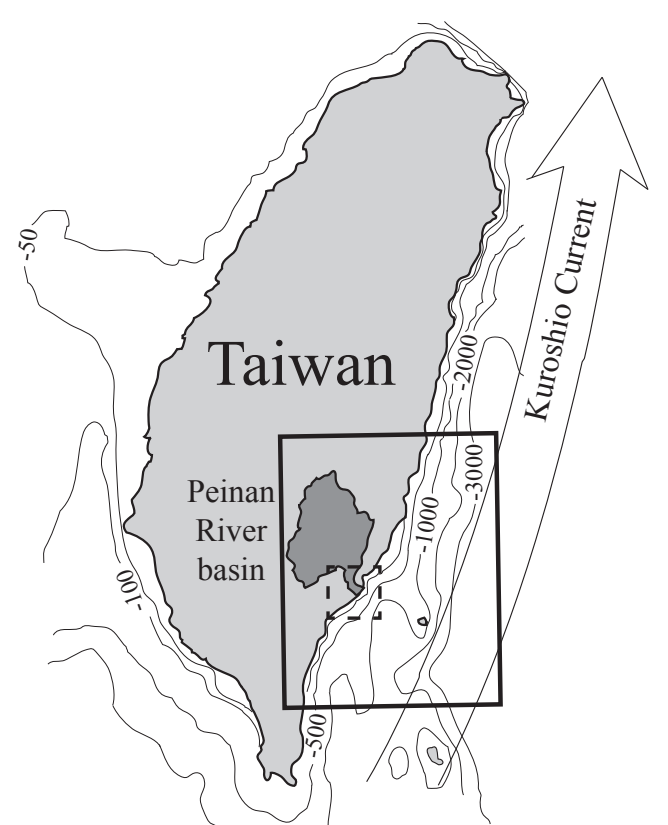

The region of numerical modeling

The region of field work

Figure 1. Bathymetry of the Taiwan coastal area and deposition of the study regions at the steep southeastern shore adjacent to the Peinan River estuary.

winter, it moves significantly offshore from the southeastern coast of Taiwan.

The mean Kuroshio central position (KCP) is located at about $122.1^{\circ} \mathrm{E}$ southeast of Taiwan and at about $122.9^{\circ} \mathrm{E}$ northeast of Taiwan, generally following the eastern coastline (Fig. 1). The largest variability of KCP occurs in the area south of $23^{\circ} \mathrm{N}$ (Hsin et al, 2013), i.e., within the study region of the current work. The climatology of velocity of $\mathrm{KC} \mathrm{ob-}$ tained from in situ measurements is rather complex, indicating a multicore structure and several branches of $\mathrm{KC}$ located to the east of Taiwan (Yuan et al., 1996, 1998; Rudnick et al., 2011).

As KC sweeps off the southern tip of Taiwan, the main stream passes through the gap between the Taiwan and the Green Island (Fig. 2). The speed of $\mathrm{KC}$ in this region is about $1.0 \mathrm{~ms}^{-1}$ in the top layer $(0-200 \mathrm{~m}), 0.5 \mathrm{~m} \mathrm{~s}^{-1}$ in the middle layer (200-400 m), and $0.3 \mathrm{~m} \mathrm{~s}^{-1}$ in the bottom layer (400-700 m), respectively, according to field measurements (Shen, 2012). The influence of KC is recorded up to a depth of $800 \mathrm{~m}$, while water below $800 \mathrm{~m}$ is basically motionless.

The small Green Island (about $5 \mathrm{~km}$ in diameter) is located in the study region within the energetic main stream of the KC (Fig. 2). It acts as an obstacle in the stream and induces vortexes shedding downstream from the island, which can be identified through satellite imagery (Liang et al., 2003). A recirculation wake followed by a wavy tail in the lee of

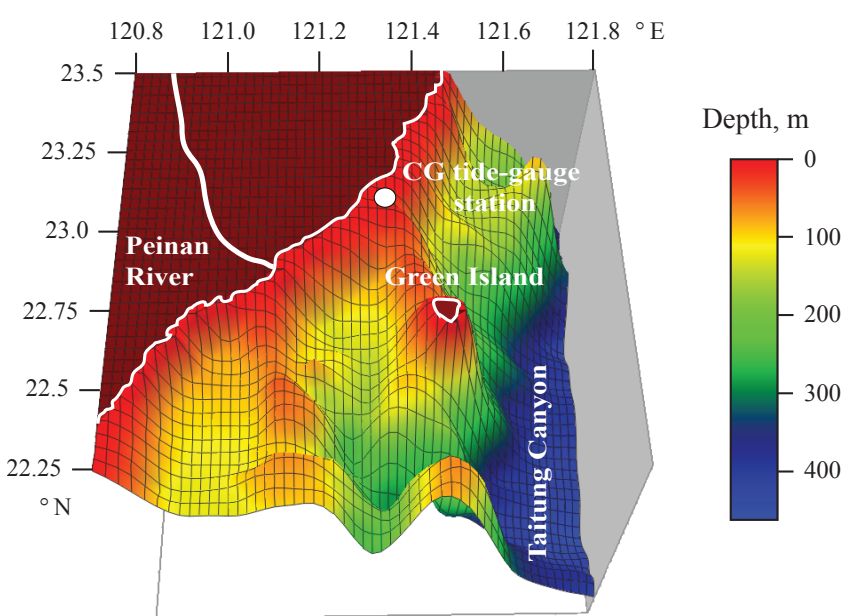

Figure 2. Bathymetry of the region of numerical modeling, illustrating deposition of the Green Island, Taitung Canyon, two submarine canyons east of the Green Island, as well as locations of the Peinan River and the CG tide-gauge station.

the island observed by satellite imagery (Jia and Liu, 2004) and field measurements (Shen, 2012) causes upwelling and enhances nitrate concentration in the upper ocean. This wake covers an area about 1-2 times greater than the Green Island and is characterized by weak surface current speeds, ranging from 0.2 to $0.5 \mathrm{~m} \mathrm{~s}^{-1}$ (Chang et al., 2013).

\subsection{Tides}

In addition to $\mathrm{KC}$, tides play a great role in coastal circulation in the study area. Tidal circulation in this region is mainly governed by four constituents, namely, two semidiurnal principal solar tides, M2 and S2, with periods 12.42 and $12.00 \mathrm{~h}$, respectively, diurnal lunisolar $\mathrm{K} 1$, and diurnal lunar O1, with periods 23.93 and $25.82 \mathrm{~h}$, respectively (Wyrtky, 1961). A combination of these four components can be used for the general description of tidal circulation in the study region.

The tidal range is small and tidal currents are weak $(\mathrm{Zu}$ et al., 2008; Hu et al., 2010) along the southeastern coast of Taiwan. Tidal sea level harmonic constants (amplitude in centimeters, phase in degrees) for $\mathrm{O} 1, \mathrm{~K} 1, \mathrm{M} 2$, and S2 were found to be equal to $14.75 / 79.2,17.54 / 101.5,20.6 / 324.8$, and $3.02 / 67.7$, respectively at the tide-gauge station CG (Hu et al., 2010) located in the study region (Fig. 2).

\subsection{River discharge}

Although principal rivers of Taiwan flow into the Taiwan Strait from the flat western coast, several mountainous rivers of the steeply sloped east coast discharge nearly the same amount of suspended sediment (about $150 \mathrm{Mt} \mathrm{yr}^{-1}$ ) into the ocean as those of the west coast $\left(130-220 \mathrm{Mt} \mathrm{yr}^{-1}\right.$ ) (Liu et al., 2008). The Peinan River is one of the biggest and the most important rivers of the east coast. Despite its modest 
length $(85 \mathrm{~km})$, basin area $\left(1600 \mathrm{~km}^{2}\right)$, and moderate mean annual freshwater runoff, varying from $30 \mathrm{~m}^{3} \mathrm{~s}^{-1}$ in spring to $170 \mathrm{~m}^{3} \mathrm{~s}^{-1}$ in summer, the Peinan River discharges a significant volume of sediments equal to $20-90 \mathrm{Mt} \mathrm{yr}^{-1}$ (Liu et al., 2008; Mirabito et al., 2012). However, river discharge and sediment runoff rates sharply increase during short-term typhoon events that frequently occur in this area. For example, discharge of the Peinan River exceeded $6000 \mathrm{~m}^{3} \mathrm{~s}^{-1}$ on 9 August 2009 during Typhoon Morakot (Mirabito et al., 2012). The sediment concentration in Peinan water is particularly high following intense precipitation events and can exceed $10 \mathrm{~g} \mathrm{~L}^{-1}$ (Dadson et al., 2005; Milliman and Kao, 2005).

\subsection{Bathymetry}

Bathymetry of the study region is very complex. For modeling, we chose unfiltered $1 / 60^{\circ}$ resolution (ETOPO1, NOAA) bottom topography. The model domain, as shown in Fig. 2, away from the shoreline, reveals the wavy deepening relief with two canyons stretched meridionally along 121 and $121.3^{\circ} \mathrm{E}$ and separated by an underwater ridge. The model domain includes the Green Island located at $22^{\circ} 50^{\prime} \mathrm{N}$ and $121^{\circ} 80^{\prime} \mathrm{E}, 40 \mathrm{~km}$ off the southeastern coast of Taiwan. At the eastern flank of the domain, the continental slope descends from a depth of 1000 to $4000 \mathrm{~m}$.

Both canyons merge into the large Taitung Canyon, through which a large volume of sediments derived from the Taiwan mountain belt is transported, including heavy sediments and pollutants, transported by the Peinan River waters (Sibuet et al., 2004).

\section{In situ data}

A field survey was conducted on 15-17 April 2014 in the study area using two local fishery boats. Daily measurements included the continuous recording of temperature, salinity, and turbidity in the upper layer along the ship track in the coastal area, influenced by the Peinan buoyant plume using a pump-through CTD system equipped with YSI-6600V2 and YSI EXO-2 instruments. In addition, vertical CTD profiling from surface to $25 \mathrm{~m}$ depth (or to the seabed at shallower stations) and water sampling were performed at the 14 stations situated as shown in Fig. 3.

A portable meteorological station, continuously recording principal meteorological parameters (wind speed and direction, atmospheric pressure, air temperature and humidity) as $10 \mathrm{~min}$ averages, was mounted about $10 \mathrm{~m}$ above sea level at the top of an old lighthouse, $2.5 \mathrm{~km}$ north of the Peinan River estuary (Fig. 3).

The obtained data sets were used for the validation of the numerical model which reproduces the dynamics of the Peinan River plume. The detailed description of the model

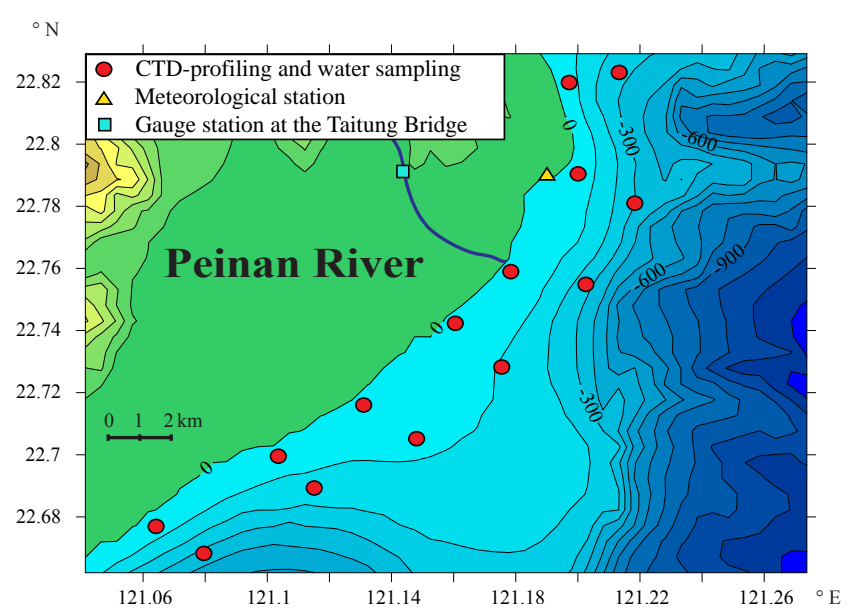

Figure 3. Bathymetry and location of stations in the region of field work conducted on 15-17 April 2014.

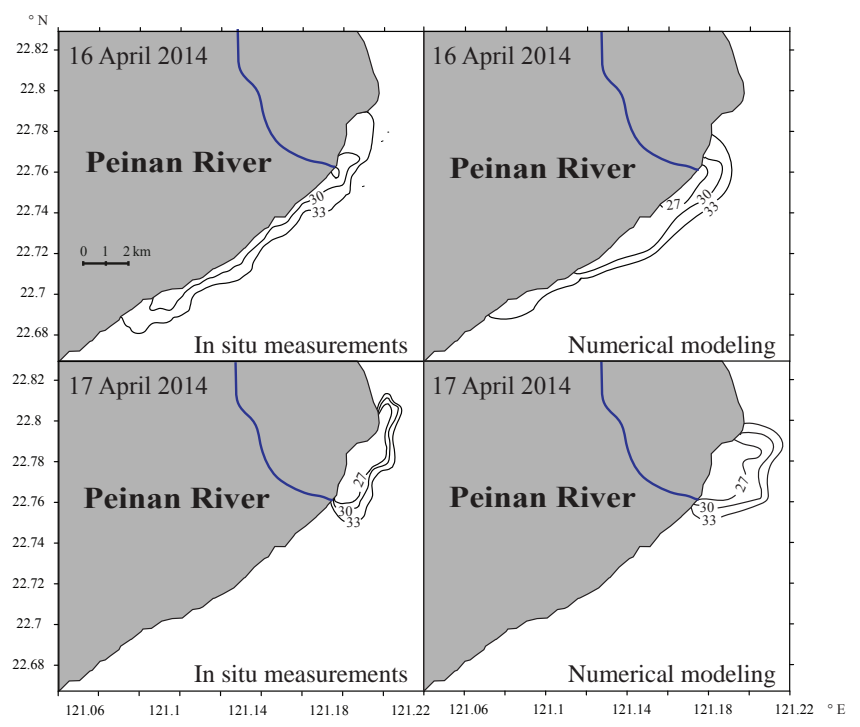

Figure 4. Surface salinity distribution (27, 30, and 33 PSU isolines), illustrating deposition and internal structure of the Peinan River plume obtained from the in situ measurements (left panels) and simulated by the numerical model (right panels) on 16 April 2014 (top panels) and 17 April 2014 (bottom panels).

validation and comparison of simulation results with the in situ measurements are given in Sect. 5.1.

The shape, position, and spatial extent of the Peinan River plume showed significant variability during the field survey (Figs. 4 and 6). On 15-16 April 2014, the freshwater plume (defined here as the area where salinity was below 33 PSU) was well-developed and stretched along the shore in the southwestern direction from the river mouth. Its alongshore extent and cross-shore width were about 16 and $3 \mathrm{~km}$, respectively. The inner part of the plume formed a salinity front (25-30 PSU) near the river estuary. On the next day, 17 April 2014, the observed plume was arrested near the estu- 


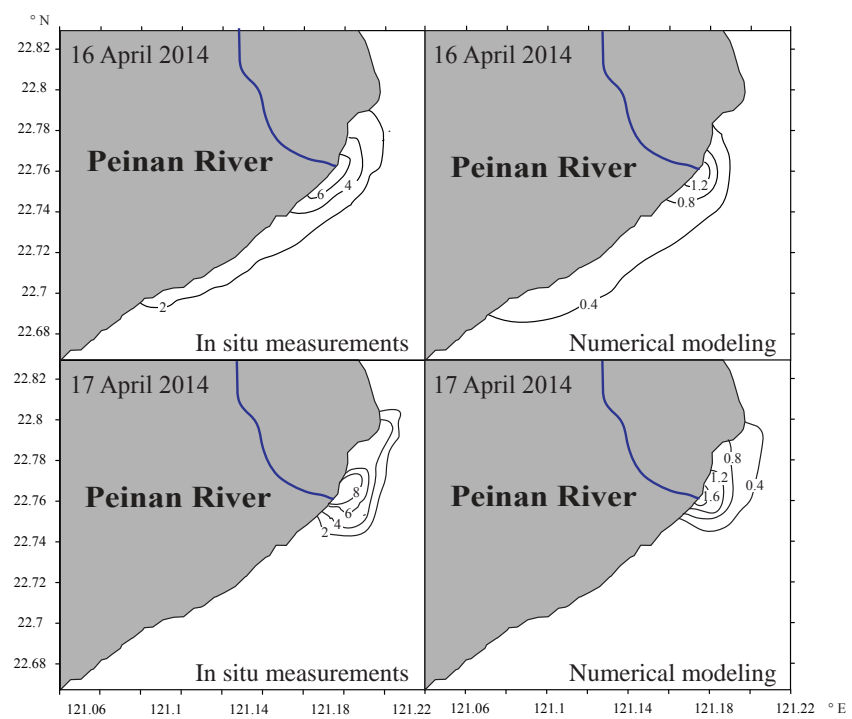

Figure 5. Surface distribution of turbidity obtained from the in situ measurements (left panels; 2, 4, 6, and 8 NTU isolines) and suspended sediment concentration simulated by the numerical model (right panels; 0.4, 0.8, 1.2, and $1.6 \mathrm{~g} \mathrm{~L}^{-1}$ isolines) on 16 April 2014 (top panels) and 17 April 2014 (bottom panels).

ary and propagated only slightly in the northeastern direction. The plume area decreased to a quarter of its previous size; however, salinity of the inner part of the plume also significantly decreased and was less than 10 PSU. The observed variability of the Peinan River plume was apparently connected with the intensification of wind forcing, which took place on 16 April. The increase of wind stress from less than 0.005 to about $0.02 \mathrm{~N} \mathrm{~m}^{-2}$ resulted in amplification of the plume dispersal and caused the development of strong offshore currents and subsequent coastal upwellings.

\section{Model}

As it was mentioned in Sect. 1, transport of fine sediment discharged from a river has two different phases, one governed by dynamics of buoyant river plume and the other one by ambient coastal circulation. This is the reason for the joint use of two nested numerical models which complement each other. The outer model is a well-known finite difference $\sigma$ coordinate Princeton ocean model (POM), which reproduces general ocean circulation along the northeastern coast of Taiwan with spatial resolution of $1 \mathrm{~min}$ in latitude and longitude. The outcome from POM provides boundary conditions for the inner Surface-Trapped River Plume Evolution model (STRiPE), which is focused on high-resolution simulation of dynamics of a buoyant river plume. Transport and settling of fine sediment within the nested model is simulated using a combination of a deterministic approach, representing the tracking of a passive tracer (James, 2002) and a stochastic random-walk scheme, parameterizing spatially nonuniform turbulent mixing (Ross and Sharples, 2004). The detailed description of model configuration and its implementation in the present study is given below.

\subsection{POM module}

The POM module consists of a three-dimensional primitive equation ocean model with a level 2.5 Mellor-Yamada turbulence closure scheme (Mellor and Yamada, 1982; Blumberg and Mellor, 1987) and the implementation of complete thermodynamics. The model domain covers the area from 120.9 to $122.0^{\circ} \mathrm{E}$ and from 22.3 to $23.5^{\circ} \mathrm{N}$ (Fig. 2) and has three open boundaries at the northern, western, and southern borders of the region. It is divided into $68 \times 75$ grid cells with a size of 1 arcmin in both longitudinal and latitudinal directions, i.e., the zonal and meridional resolutions are equal to $1.723 \mathrm{~km}\left(\right.$ at $\left.23^{\circ} \mathrm{N}\right)$ and $1.836 \mathrm{~km}$, respectively. The vertical coordinate is represented by $31 \sigma$-levels with irregular vertical spacing. The $\sigma$-levels encompass the water column from 5 to $4860 \mathrm{~m}$ stretching in the upper and near-bottom levels for the realistic reproduction of surface and bottom boundary layers. The time steps were set equal to 3 and $120 \mathrm{~s}$ for the external and internal modes, respectively.

The vertical eddy viscosity and diffusivity were provided by the level 2.5 Mellor-Yamada turbulence closure scheme with a background value of $10^{-5} \mathrm{~m}^{2} \mathrm{~s}^{-1}$. The horizontal eddy viscosity $K_{L}$ was calculated using the embedded Smagorinsky formula (1963):

$K_{L}=C_{H} \Delta x \Delta y \sqrt{\left(\frac{\partial U}{\partial x}\right)^{2}+\left(\frac{\partial V}{\partial y}\right)^{2}+\frac{1}{2}\left(\frac{\partial U}{\partial y}+\frac{\partial V}{\partial x}\right)^{2}}$,

where $U$ and $V$ are the horizontal components of the timeaveraged velocity and $C_{H}$ is a scaling parameter equal to 0.1 . Horizontal eddy diffusivity was obtained using the inverse Prandtl number of 0.5 .

As was mentioned above, the submarine canyons and ridges stretching along the shore are important features of the bottom topography. They may significantly affect the structure of the alongshore flow and mixing governed by the interacting tidal circulation and KC. Therefore it is important to adequately simulate bottom stress in order to represent these effects.

In the POM module, bottom friction is determined by the current velocity of the layer closest to the seabed using the assumption of a logarithmic current profile in the following way. The stress components $\tau_{\mathrm{b}}^{x}$ and $\tau_{\mathrm{b}}^{y}$ induced by the bottom friction are described as

$$
\left(\frac{\tau_{\mathrm{b}}^{x}}{\rho}, \frac{\tau_{\mathrm{b}}^{y}}{\rho}\right)=C_{z}\left(U^{2}+V^{2}\right)^{1 / 2}(U, V),
$$

where $C_{z}$ is a dimensionless coefficient, dependent on the roughness length of the bed $z_{0}$ and the water depth $H$. The 
16 April 2014

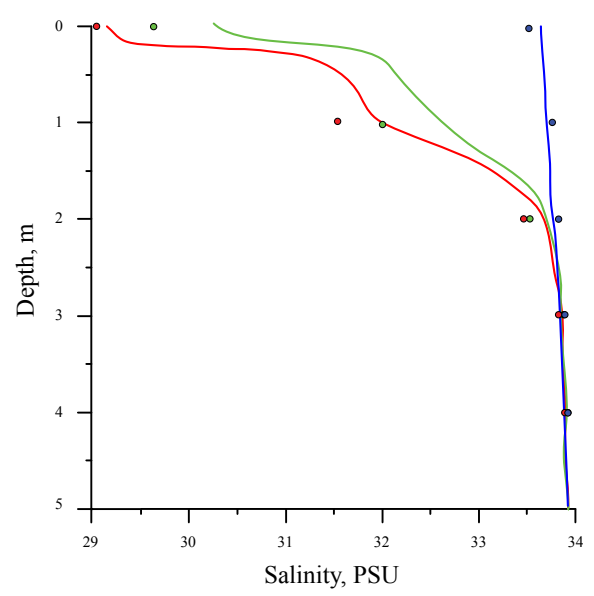

Suspended sediment concentration, $\tilde{g}^{-1} 1$

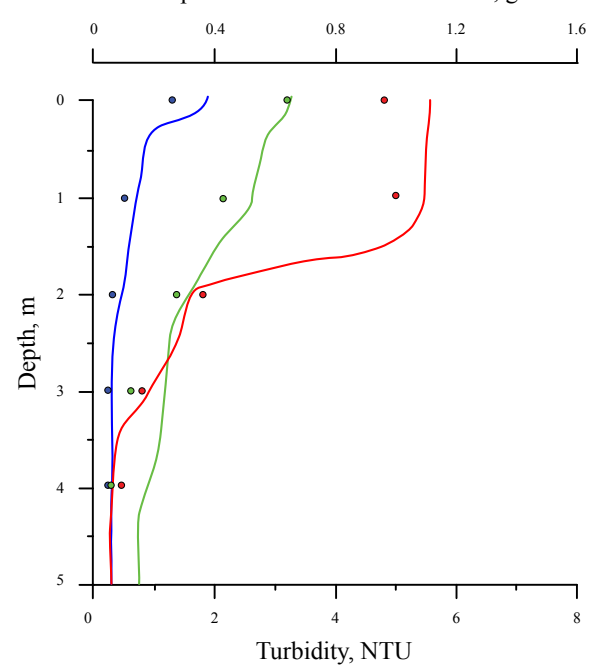

17 April 2014
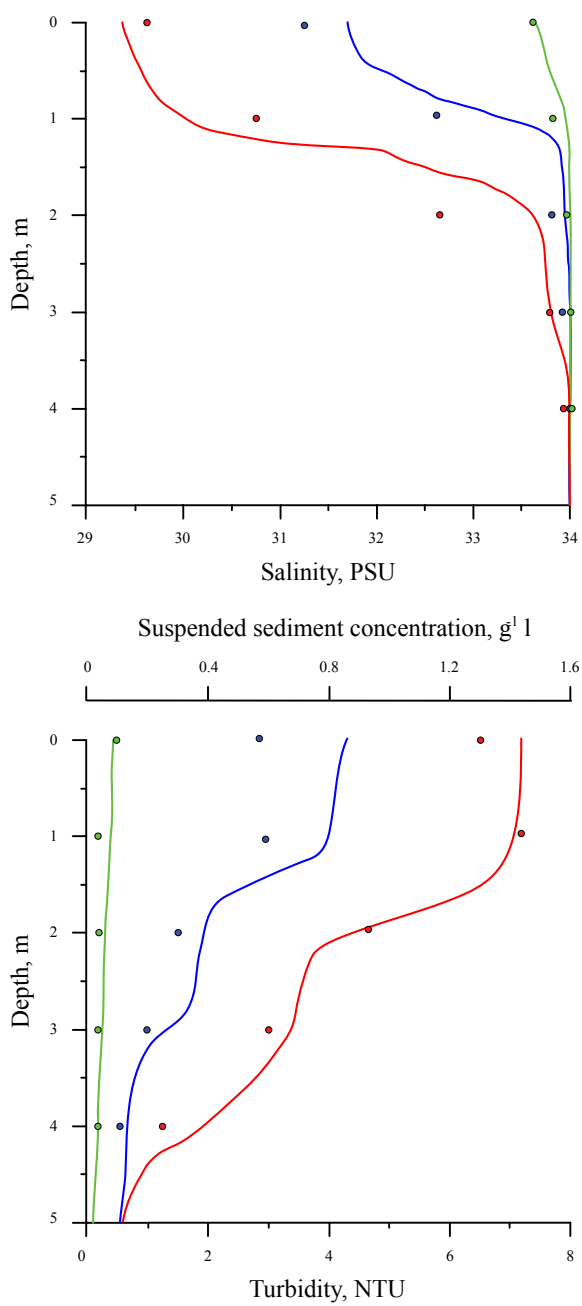

Figure 6. Vertical profiles of salinity (top panels) and turbidity (bottom panels) obtained from the in situ measurements (solid lines) at stations 8 (green), 10 (red), and 12 (blue) on 16 April 2014 (left panels) and 17 April 2014 (right panels) and the related values of salinity (top panels) and suspended sediment concentrations (bottom panels) simulated by the numerical model (circles). A value of 1 NTU of the in situ turbidity measurements was assumed to correspond to value of $0.2 \mathrm{~g} \mathrm{~L}^{-1}$ of the simulated suspended sediment concentration.

coefficient $C_{z}$ is given by the following formula:

$C_{z}=\max \left(\frac{\kappa^{2}}{\left.\left\{\ln \left[\left(1+\sigma_{k b-1}\right) H / z_{0}\right)\right]\right\}^{2}}, 0.0025\right)$,

where $\kappa$ is the von Karman constant equal to 0.4 and $\sigma_{k b-1}$ is the depth of the layer overlaying the sea bottom in sigma coordinates.

Temperature and salinity boundary conditions applied at the open boundaries of the calculation domain were different for inflow and outflow fluxes (Fig. 2). Temperature $T$ and salinity $S$ of inflow water were set equal to the corresponding open boundary values, while in the case of outflow from the domain, the radiation equation was used:

$\frac{\partial}{\partial t}(T, S)+U_{n} \frac{\partial}{\partial n}(T, S)=0$, where $n$ represents the direction normal to the open boundary. The radiation boundary conditions are based on the principle of propagation of a long gravity wave, which is used to specify sea level oscillations in the form of a combination of values of level elevations and a normal current velocity component at the open boundaries.

The vertically averaged barotropic velocities at the open boundaries of the model domain were estimated using the Flather (1976) formula:

$\bar{U}_{\mathrm{n}}=\bar{U}_{\mathrm{n}}^{0}+\sqrt{\frac{g}{H}}\left(\eta-\eta_{0}\right)$,

where $\bar{U}_{\mathrm{n}}$ is the vertically averaged normal component of the time-averaged horizontal velocity at the open boundary at the 
time moment $t, \bar{U}_{\mathrm{n}}^{0}$ is the initial vertically averaged normal component, $\eta$ is the model sea surface elevation calculated using the continuity equation and located half of a grid inside of the open boundary in the model domain, $\eta_{0}$ is the sea surface elevation at the open boundary of the model, $H$ is the water depth at the open boundary, and $g$ is the gravitational acceleration. Open boundary conditions $\bar{U}_{\mathrm{n}}^{0}$ and $\eta_{0}$ were implemented from the barotropic tidal model (Hu et al., 2010), developed in Tainan Hydraulics Laboratory, National ChengKung University and kindly provided by Liu et al. (2014).

In this model study we mimicked the Kuroshio Current by specifying an additional surface velocity along the southern boundary of the model domain based on observational data and numerical experiments (Yuan et al., 1998; Johns et al., 2001). The additional velocity was determined in the following way. It linearly increased with the distance from the coast, i.e., from $0 \mathrm{~m} \mathrm{~s}^{-1}$ at the westernmost wet grid point to $0.4 \mathrm{~m} \mathrm{~s}^{-1}$ at the easternmost grid point of the eastern boundary. In the vertical dimension, we used linearly decreasing velocity from surface to bottom. Since the Kuroshio core is situated beyond the eastern boundary of the model domain, we can apply the simplification described above.

\subsection{STRiPE module}

STRiPE is a Lagrangian model developed for simulating river plumes under various forcing conditions (Osadchiev and Zavialov, 2013). It represents a river plume as a set of Lagrangian particles or homogeneous elementary water columns extending from the surface down to the boundary between the plume and the underlying sea water. These particles are released from the river mouth, with the initial velocity depending on the river discharge rate. Then they are tracked by the model according to the momentum equations, including the main forces that are applied to individual particles and determine river plume dynamics, namely, the Coriolis force, the wind stress force, the friction with the underlying layer, the lateral friction, the pressure gradient force, and small-scale horizontal turbulent mixing parameterized by the random-walk method. The background velocity field, which is necessary for calculating bottom friction, is imported from POM simulations as input data. At every step of the model integration, the overall set of particles represents the river plume; hence the temporal evolution of the plume structure is obtained. Horizontal turbulent diffusivity $K_{\mathrm{h}}$ used in the random-walk scheme is parameterized by the Smagorinsky diffusion formula described in Sect. 3.1. Vertical mixing with the ambient seawater is parameterized by the salinity diffusion equation:

$$
\frac{\partial S}{\partial t}=K_{\mathrm{v}} \frac{\partial^{2} S}{\partial z^{2}},
$$

where $S$ is the salinity and $K_{\mathrm{v}}$ is the vertical diffusion coefficient parameterized via the Richardson number $R i$ and scal- ing coefficient $C_{\mathrm{v}}$, as given by Large (1994):

$D_{\mathrm{v}}=C_{\mathrm{v}}\left(1-\min \left(1, R i^{2}\right)\right)^{3}$.

The detailed description of the STRiPE is given in Osadchiev and Zavialov (2013). This model coupled with POM was recently used to study dynamical features of the Zhuoshui and $\mathrm{Wu}$ river plumes located on the western part of the Taiwan coast (Korotenko et al., 2014).

\subsection{Sediment transport module}

The transport and settling of fine suspended sediments discharged from the river mouth is simulated using a Lagrangian particle-tracking module. Both horizontal and vertical movements of a sediment particle are calculated using a combination of a deterministic component defined by motion of ambient water and sinking of a particle under the gravity force and a stochastic random-walk scheme that reproduces influence of small-scale turbulent mixing. Particles are initially released from the river mouth and their horizontal transport is determined by internal dynamics of a river plume simulated by the STRiPE module. We presume strong mixing in river water before it inflows into the sea, therefore particles have homogenous vertical distribution in the inflowing water. Initial concentration of particles in river water was evaluated according to the following equation (Nash, 1994):

$C=a Q^{b}$,

where $C$ is the sediment concentration in river water, $Q$ is the river discharge volume, and $a$ and $b$ are the scaling coefficients.

During its motion a particle sinks within the river plume until it reaches the mixing zone between the river plume and the underlying sea waters. After the particle descends beneath the lower boundary of the plume, its horizontal motion is determined by ambient coastal circulation calculated by the POM module. In this study we focus on relatively small particles with diameter less than $10^{-4} \mathrm{~m}$; therefore, gravityinduced vertical motion is determined by a Stokes' law, and particle-settling velocity $w_{\mathrm{s}}$ is calculated according to the well-known formula (Stokes, 1851):

$w_{\mathrm{s}}=\frac{g d^{2}\left(\rho_{\mathrm{s}}-\rho_{\mathrm{w}}\right)}{18 \mu \rho_{\mathrm{w}}}$,

where $g$ is the gravitational acceleration, $d$ is the diameter of a sediment particle, $\rho_{\mathrm{s}}$ is the density of a sediment particle, $\rho_{\mathrm{w}}$ is the density of water, and $\mu$ is the dynamic water viscosity.

The total vertical displacement of the particle caused by sinking under gravity force, vertical circulation of ambient water, and turbulent mixing was parameterized using the following equation (Hunter et al., 1993; Visser, 1997; Ross and Sharples, 2004), which represents features of spatially 
nonuniform turbulent mixing:

$\Delta z=\left(w_{S}+\frac{\partial K}{\partial z}\right) \Delta t+\sqrt{\frac{2}{3} K_{\mathrm{v}}\left(z+\frac{1}{2} \frac{\partial K_{\mathrm{v}}}{\partial z} \Delta t\right) \Delta t \xi}$

where $\Delta z$ is the vertical particle displacement, $w_{\mathrm{s}}$ is the Stokes' settling velocity of a particle, $K_{\mathrm{V}}$ is the vertical eddy diffusivity coefficient, $\Delta t$ is the time step, $\xi$ is a random process with standard normal distribution (zero mean and unity variance) produced by a random number generator.

The sediment transport module domain covers the area from $120.9^{\circ} \mathrm{E}$ to $121.4^{\circ} \mathrm{E}$ and from $22.5^{\circ} \mathrm{N}$ to $22.9^{\circ} \mathrm{N}$ realistic shoreline. The domain topography was set with a step equal to $0.002^{\circ}$ for both latitude and longitude directions with $1 \mathrm{~m}$ accuracy.

\section{Numerical simulations}

The developed model was applied to the study region to investigate the fate of fine sediments discharged by the Peinan River. The POM module was initialized using the Antonov et al. (2010) seasonally averaged climatic temperature and salinity fields as the initial background conditions and provided the ambient velocity fields for the STRiPE and sediment transport modules.

In the STRiPE module, freshwater particles containing sediment constituents were released from the Peinan River estuary according to the Manning formula with the initial inflow velocity $w=0.3\left(\frac{Q}{L}\right)^{2 / 5}$, where $Q$ is the discharge of the Peinan River and $L$ is the width of the Peinan River mouth. The initial vertical scale of the released freshwater columns (i.e., the plume thickness at the mouth) was prescribed as $h=3.3\left(\frac{Q}{L}\right)^{3 / 5}$. Initial sediment concentration in the inflowing river waters was calculated according to Eq. (8); the coefficients $a=0.25$ and $b=0.6$ for $Q<500 \mathrm{~m}^{3} \mathrm{~s}^{-1}$ and $a=0.02$ and $b=1.0$ for $Q>500 \mathrm{~m}^{3} \mathrm{~s}^{-1}$, specifying the dependence between river discharge and sediment concentration for the Peinan River under freshet and typhoon conditions, were taken from Hwang (1982) and Milliman and Kao (2005), respectively based on gauge measurements performed at the Taitung Bridge (Fig. 3). Densities of river and ambient sea waters were set equal to 1000 and $1034 \mathrm{~kg} \mathrm{~m}^{-3}$, respectively, while sediment density was prescribed as $2300 \mathrm{~kg} \mathrm{~m}^{-3}$. The latter value was calculated based on dry bulk density of sediments delivered by Taiwan rivers to the surrounding seas, which was prescribed as being equal to $1600 \mathrm{~kg} \mathrm{~m}^{-3}$ (Liu et al., 2008), and sediment porosity which was set equal to 0.3 (Jiang et al., 2006). Initial grain distribution of fine sediments was prescribed according to the results of analysis of the water samples taken at the $1 \mathrm{~m}$ depth at the station situated $500 \mathrm{~m}$ offshore from the Peinan River mouth (Fig. 3). Kinematic viscosity of water was set equal to $10^{-6} \mathrm{~m}^{2} \mathrm{~s}^{-1}$. The integration time steps for the STRiPE and sediment transport modules were set to $10 \mathrm{~min}$.
The numerical experiments were organized in the following way. Firstly, we validated the model against the in situ data collected during the field survey. Then we simulated the behavior of the Peinan River plume and the associated transport of fine sediments under average summer freshet and typhoon conditions.

\subsection{Validation}

The first simulation was performed under wind forcing and Peinan discharge rate, observed during field work at the meteorological and gauge stations located close to the Peinan estuary (Fig. 3). The period of 15-17 April 2014 was dominated by a southwesterly wind; its speed ranged from 0.5 to $6 \mathrm{~m} \mathrm{~s}^{-1}$. During this period the Peinan River had constant discharge equal to $21 \mathrm{~m}^{3} \mathrm{~s}^{-1}$.

The behavior of the Peinan River plume during 15-17 April 2014 was simulated by the STRiPE module using in situ wind and discharge data and POM-generated current velocity field. The numerical modeling adequately reproduced submesoscale spatial variability of the Peinan River plume observed during the field survey. The Peinan plume was stretched along the shore in a southwestern direction on 1516 April, however upwelling-favorable southwestern winds resulted in a shift of the plume to the north of the Peinan estuary, a widening of the plume on 17 April, and an increase of its salinity anomaly near the estuary. The average positions of the simulated plume corresponding to 16 and 17 April 2014 illustrate this dramatic displacement and show good agreement with the salinity maps of the region obtained from the continuous CTD measurements in the surface layer (Fig. 4).

The simulated sediment distribution within the plume was also validated against in situ data. For this purpose we used turbidity measurements performed during the field work at the surface layer and compared them with simulated concentrations of suspended sediments. A turbidity value of 1 NTU was assumed to correspond to a suspended concentration value of $0.2 \mathrm{~g} \mathrm{~L}^{-1}$ based on the analysis of water samples taken at station 10. Both field data and numerical modeling showed that surface waters with elevated turbidity corresponded to the position of the plume during the whole simulation period (Fig. 5). Sediment concentration in proximity to the river estuary increased after the shift of the plume on 17 April 2014, which was reproduced by numerical modeling.

Vertical haline structure of the Peinan plume and vertical sediment distribution were also consistent with the available in situ data. In particular, dramatic changes of vertical salinity and turbidity profiles measured in proximity of the Peinan River estuary, namely, at stations 8, 10, and 12, during 1617 April were adequately simulated by the numerical model (Fig. 6). Generally, the validation experiment demonstrated the ability of the developed model to reproduce dynamics of the Peinan River plume well. 


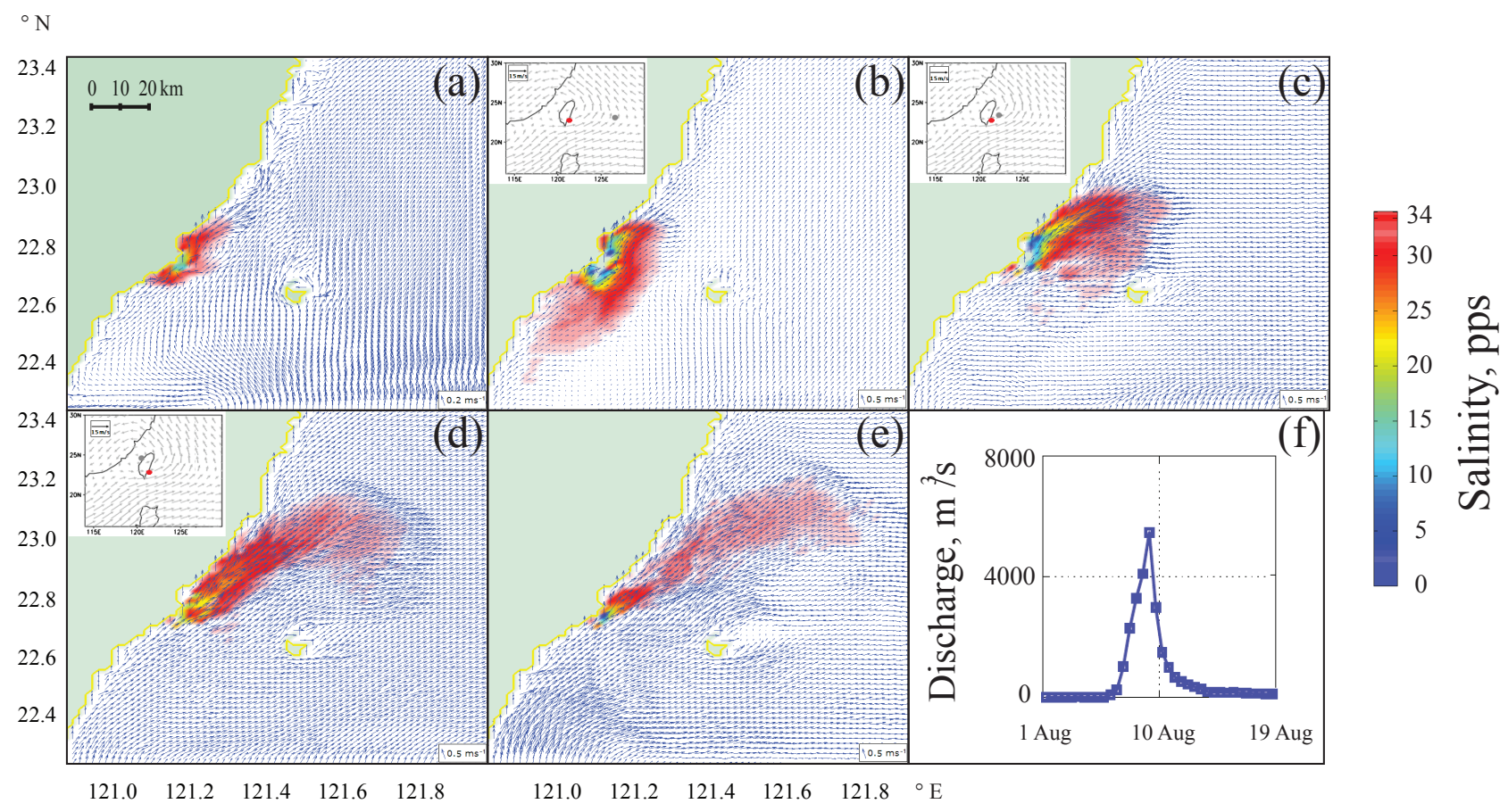

Figure 7. The Peinan River plume under typhoon conditions before (a), on the first (b), the second (c), the third (d), and the fifth (e) day of typhoon simulation. The left bottom panel (f) shows the discharge rate of the Peinan River in August 2009 during Typhoon Morakot (after Mirabito et al., 2012). Deposition of the center of the $700 \mathrm{hPa}$ typhoon (gray solid dot) and the Peinan River estuary (red solid star) are shown in the insets in (b)-(d) (after Wu et al., 2011).

\subsection{Numerical experiments}

After validation of the model, we performed two numerical experiments simulating the fate of river-borne sediments under moderate and flooding discharge conditions of the Peinan River. The first simulation of sediment transport under moderate discharge conditions was executed using average August discharge of the Peinan River $\left(80 \mathrm{~m}^{3} \mathrm{~s}^{-1}\right)$ and average climatic wind conditions (NE wind, $2.0 \mathrm{~m} \mathrm{~s}^{-1}$ ). The first experiment was performed for a period of 30 days.

Model configuration for the second numerical experiment reproducing sediment transport under flooding discharge conditions was more complex. Initially, the plume was modeled under average August climatic conditions for a period of 3 days. After that, we simulated 6 days of flooding conditions using wind forcing and discharge rate of the Peinan River observed on 4-9 August 2009, when Typhoon Morakot was passing over Taiwan. Next, during the relaxation period, the model was forced again by mean climatic conditions for August. Typhoon Morakot induced rainfall over the eastern coast of Taiwan and led to unprecedented rainfall and subsequent flooding in southern Taiwan (Wu et al., 2011). The discharge rate of the Peinan River peaked from the annual mean of 80 to $6000 \mathrm{~m}^{3} \mathrm{~s}^{-1}$, while a maximal intensity of wind exceeded $40 \mathrm{~m} \mathrm{~s}^{-1}$ (Mirabito et al., 2012).

Figure 7f adopted from Mirabito et al. (2012) illustrates the discharge rate of the Peinan River before, during, and af- ter Typhoon Morakot. Fast and almost uniform increase of discharge of the Peinan River during 7-9 August 2009 was followed by its exponential decrease during 10-16 August 2009. In particular, river discharge sharply dropped during 10 August and then slowly decreased during the following 5 days to the seasonally averaged value. Therefore the decrease rate of the discharge was significantly slower than the increase rate during the whole period except on $10 \mathrm{Au}-$ gust 2009. The same feature was observed for a number of other Taiwan rivers during Typhoon Morakot (e.g., Gaoping, Zhuoshui, Zengwen, Wu) and was possibly caused by inhomogeneous precipitation distribution during passage of Typhoon Morakot over Taiwan and by relatively small lengths and basin areas of Taiwan rivers (Mirabito et al., 2012).

The hydrodynamical model showed a significant impact of typhoon conditions on the sea circulation east of Taiwan and the behavior of the Peinan plume. Strengthening of southwesterly winds over the study area and an increase of the Peinan River discharge induced by the typhoon resulted in a tremendous change of local circulation and considerable elongation of the Peinan plume (Fig. 7). Initially, the bulgelike river plume was stretched northwardly along the shore under the action of average climatic winds (Fig. 7a). The interaction of wind drift current and buoyancy resulted in a strong jet-like alongshore current north of the Peinan estuary. 
The increase of wind stress and change of its direction during the first day of the typhoon caused the plume to widen, to shift in a southerly direction, and to detach from the shore (Fig. 7b). During the second typhoon day, the plume moved in a northeasterly direction, its newly formed part adjacent to the Peinan estuary propagated along the coast, while the older part formed a round-shaped bulge, of which extension reached the Green Island (Fig. 7c). The third flooding day was characterized by peaks of wind speed, river discharge, and velocity of coastal circulation $\left(1 \mathrm{~m} \mathrm{~s}^{-1}\right)$. For this day, the plume was stretched northeastwardly and detached from the coast near $23^{\circ} \mathrm{N}$ (Fig. 7d). Figure 7e shows the Peinan plume on 10 August 2009 when discharge rate decreased below $2000 \mathrm{~m}^{3} \mathrm{~s}^{-1}$, but wind remained strong, with its speed exceeding $10 \mathrm{~m} \mathrm{~s}^{-1}$. During this period the meandering plume became unstable in its near-field and was broken into several patches. The far-field of the plume remained consolidated, but its salinity contrasts with the ambient water noticeably diminished. After the departure of the typhoon from the study area, the northeastward current decreased gradually during several following days. The Peinan plume tended to return to its position and shape, as it was before the typhoon (Fig. 7a).

The simulated spread of the Peinan River discharge in coastal waters during Typhoon Morakot showed similar characteristics with the discharges of other large Taiwan rivers. As described in Chien at al. (2011) and Jan et al. (2013), major rivers of western Taiwan, namely, the Zhuoshui, $\mathrm{Wu}$, Tsengwen, and Gaoping rivers, formed large buoyant plumes. Together with surface-advected plumes, these rivers (characterized by elevated suspended sediment concentration) also produced hyperpycnal flows (Milliman and Kao, 2005; Carter et al., 2012), which, however, lie beyond the scope of our current research. Horizontal $(\sim 100 \mathrm{~km})$ and vertical $(\sim 10 \mathrm{~m})$ spatial scales, as well as the salinity anomaly ( $\sim 2$ PSU) of the far-field part of the buoyant plume, formed by the Zhuoshui River and based on in situ measurements performed on 13-17 August 2009, are the same as those simulated by the numerical model for the Peinan plume shortly after Typhoon Morakot (Fig. 7e) (Jan et al., 2013). Lifetimes of these large freshwater plumes were also similar; they returned to their pre-typhoon states about 1-1.5 weeks after river discharges dropped to their average monthly values (Jan et al., 2013).

\section{Results and discussion}

\subsection{Sediment deposition}

The obtained simulation results of river-borne sediment delivery after 30 days of freshet conditions and 6 days of the typhoon are presented in Fig. 8. Sediment outflow concentration in the Peinan River water was about $4 \mathrm{~kg} \mathrm{~m}^{-3}$ during the moderate discharge simulation, which results in $0.8 \times 10^{6}$ tons of sediment discharge for the period of 30 days. Ty-

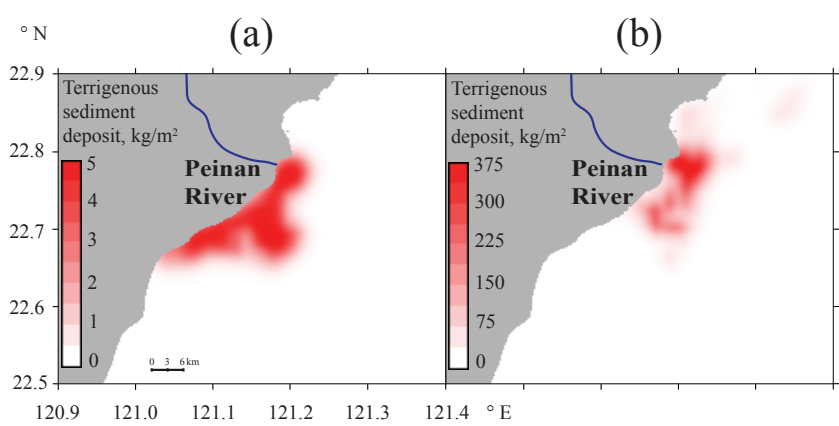

Figure 8. Simulated distribution of fine sediments deposited to the seabed in the study area under moderate (a) and flooding (b) forcing conditions.

phoon conditions were characterized by a dramatic increase in river runoff and sediment concentration, with corresponding peak values of about $6000 \mathrm{~m}^{3} \mathrm{~s}^{-1}$ and $120 \mathrm{~kg} \mathrm{~m}^{-3}$. The total sediment influx during the 6 typhoon days was about $20 \times 10^{6}$ tons, which is 25 times greater compared to the moderate discharge simulation for 30 consecutive days. As a result, the sediment accumulation rate under typhoon discharge conditions was about 2 orders of magnitude greater, compared to average freshet discharge.

The resulting deposit patterns obtained by the two model runs were significantly different. During the freshet discharge period, river-borne sediments were almost homogenously deposited in the shallow area in the southern and southwestern directions of the river estuary. The alongshore extent of the area influenced by active sediment load (3$5 \mathrm{~kg} \mathrm{~m}^{-2}$ ) exceeded $25 \mathrm{~km}$. Total sediment load to the seabed at the study area was about $0.5 \times 10^{6}$ tons, while $0.3 \times 10^{6}$ tons of fine sediments remained in the water column and did not settle on the sea floor during the simulation period.

The most active sediment load during and shortly after the typhoon period took place within the small area adjacent to the Peinan River estuary. The spatial scale of this area was only $5 \mathrm{~km}$; however, the mass of sediment that settled to the bottom exceeded $300 \mathrm{~kg} \mathrm{~m}^{-2}$. A large volume of sediment was also transported form the Peinan River mouth along the shore in southwesterly and northeasterly directions and settled on the seabed at the corresponding shallow shelf areas. The spatial extents and bottom sediment concentrations at the considered coastal zones influenced by active sediment loads were equal to $10 \mathrm{~km}$ and $150-250 \mathrm{~kg} \mathrm{~m}^{-2}$ for the southwestern zone and $5 \mathrm{~km}$ and $50-150 \mathrm{~kg} \mathrm{~m}^{-2}$ for the northeastern zone. However, only about $8 \times 10^{6}$ tons of the total sediment discharge volume settled on the sea floor within the study area, while $12 \times 10^{6}$ tons were transported offshore to the deeper sea and remained in the water column.

The presented simulation results show that sediment deposition patterns for both model runs significantly depend on the river plume dynamics. Under freshet discharge conditions and moderate wind forcing, the alongshore transport of the 


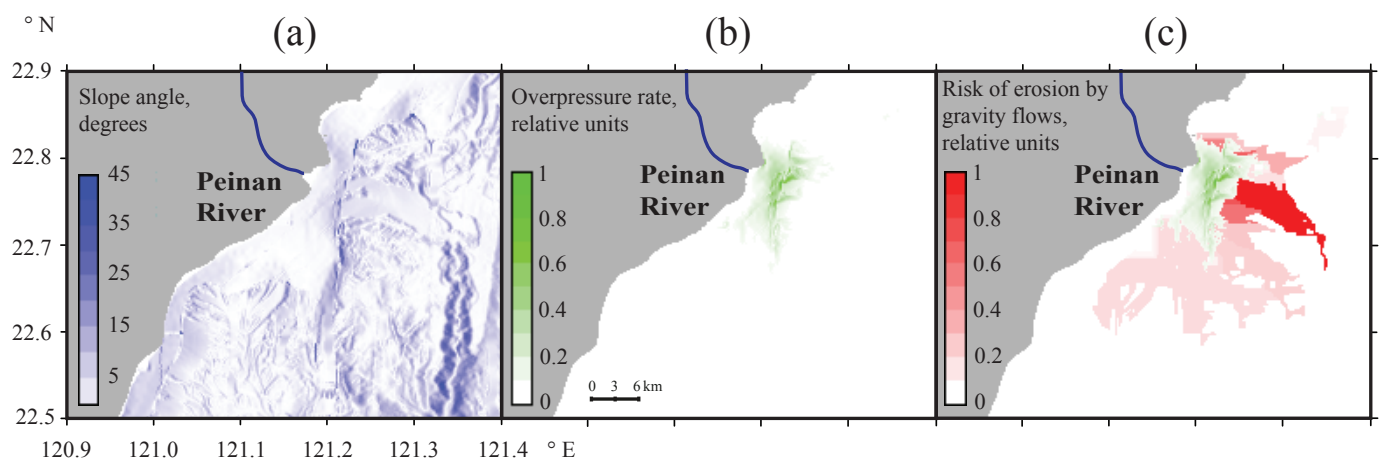

Figure 9. Bottom topography gradient at the region of numerical modeling (a), distribution of the overpressure rate (b) after typhoon conditions and potential paths of the related gravity flows (c).

Peinan plume is generally in geostrophic balance. As a result, river-borne sediments, which are initially concentrated in the upper layer, are transported by the plume in the southwestern direction. Once sediment particles sink beneath the plume, their motion is determined by the northeastward coastal circulation governed by the KC. The average velocity of coastal currents below the upper layer is significantly lower than the velocity of the river plume propagation. Therefore, sediment particles settled from the plume to the underlying waters in shallow coastal areas located to the southwest of the Peinan estuary are only slightly displaced by coastal currents in the northeastern direction and are finally deposited to the seabed in this area. Conversely, a significant portion of sediments at the study region is transported by the plume offshore from the narrow continental shelf. Once these sediment particles sink beneath the plume at deeper ocean, they are moved away in the northeastward direction by the strong alongshore current and do not settle on the sea floor within the study region.

Elevated discharge of terrigenous sediments to the sea during typhoon conditions resulted in increased sediment deposit in the study area. However, the rate of deposited sediments in respect to the total discharge $(40 \%)$ was significantly lower compared to the freshet conditions $(65 \%)$ because of the following reasons. Typhoon conditions are characterized by strong winds, which governed the spread of the Peinan plume in the study region. During the simulation period, the Peinan plume propagated mostly in the northeastern direction; therefore the river-borne sediments settled mainly in the small shallow area immediately adjacent to the river plume. Also, the plume propagation velocity was significantly higher compared to the freshet conditions; therefore, the major part of the sediments did not sink beneath the plume within this shallow area and were transported offshore to the deeper ocean. Finally, strong wind forcing induced active turbulence at the upper layer, which reduced settling speed of the sediment particles. A short period of northern winds during the typhoon resulted in active sediment deposition at the shallow coastal area situated to the south from the Peinan estuary, however, the volume of sediment load in this area was much less compared to the area adjacent to the Peinan estuary. The obtained simulation results are consistent with the findings of the previous studies (Milliman and Kao, 2005; Kao et al., 2008) that the ratio of fine sediments deposited in coastal waters to the total sediment discharge is significantly lower during typhoon events compared with average climatic conditions.

\subsection{Submarine landslides}

One of the practical aims of this study consists of the identification of the zones in the study area which exhibit an elevated risk of formation of submarine landslides caused by elevated sediment deposit after typhoon events. Such landslides can cause auto-suspending gravity flows at the steep continental slope. For instance, two cable-breaking gravity flows were registered after Typhoon Morakot near the Gaoping River estuary in the southwestern part of Taiwan (Carter et al., 2012; Su et al., 2012). The first one happened on 9 August 2006 and was caused by a hyperpycnal flow of the Gaoping discharge, while the second one took place on 13 August 2006 and was associated with a submarine landslide of rapidly deposited sediment during and shortly after the typhoon event.

However, in this study we focus on dependences of sediment deposit patterns on external forcing conditions as one of the major preconditioning factors of the formation of a submarine landslide. Using the simulated distribution of the mass of sediment deposit we can calculate the downslope component of gravity force applied to the sediment in the following way: $F=m \cdot g \cdot \sin (\alpha)$, where $m$ is the mass of sediment deposit on the considered unit seabed area and $\alpha$ is the local bottom slope angle. This value is proportional to the rate of overpressure, which causes a submarine landslide if it exceeds a certain value, which depends on local bottom friction. Thus, seabed areas with high values of $F$ are the potential regions of formation of auto-suspending gravity flows.

We considered the distribution of $F$ for typhoon conditions because for this case, the average sliding force was several orders greater than that for sediment distributions 
formed under moderate discharge conditions. Figure 9 illustrates three characteristics which are related to the formation of submarine landslides and gravity flows, namely, the bottom topography gradient (Fig. 9a), the distribution of $F$ normalized by its maximal value in the study region (Fig. 9b), and paths of the turbidity flows potentially caused by submarine landslides within the study region (Fig. 9c). Every point of the seafloor where a submarine landslide can be potentially generated produces a single path which is assumed to propagate in the direction of the maximal topography gradient. Saturation of the color of a path corresponds to the saturation of the color of its initial point, i.e., dark/light red paths illustrate more/less likely gravity flows. If two different paths (with different saturations of their colors) go through the same point, the more plausible path is drawn.

As it can be seen from the figures, the most risky region with respect to formation of submarine landslides in the study area is located near the Peinan River estuary, which is characterized by the most active sedimentation under typhoon conditions. Pathways of the turbidity flows generated in this zone cover a large coastal area situated to the southeast of the Peinan River estuary. This area is significantly different from the potential path of the gravity flow caused by hyperpycnal Peinan plume.

Two gravity flows of different origin recorded near the Gaoping River estuary after Typhoon Morakot also had different formation points and different paths according to the locations of the underwater cable breaks. The first turbidity current was formed by a hyperpycnal flow in proximity of the river estuary, while the second one (presumably caused by a submarine landslide) originated about $10 \mathrm{~km}$ away from the estuary about 3 days after the peak discharge (Carter et al., 2012). These spatial and temporal scales are similar to our findings concerning the Peinan River.

\section{Summary and conclusions}

This study is focused on the influence of external forcing conditions on the transport and deposition of fine sediment discharged from the Peinan River on the steep northeastern coast of Taiwan. For this purpose, we used a combination of two hydrodynamic numerical models, namely, the Eulerian Princeton ocean model (POM) and the Lagrangian SurfaceTrapped River Plume Evolution (STRiPE) model. The combined model was validated against in situ measurements performed in the study area on 15-17 April 2014. Then it was used to simulate the fate of river-borne sediments discharged during a typical freshet period and during a strong typhoon. For the first numerical experiment we used average climatic August discharge and wind forcing conditions, while the second model run was performed under real forcing conditions observed during Typhoon Morakot on 4-9 August 2009.

Numerical experiments showed that the initial transport of terrigenous material is mainly governed by river plume dynamics, while its final deposition depends on the ambient coastal circulation as modulated by the local bathymetry. In particular, the most active sediment deposition at the study region took place in the shallow shelf areas. Sediment particles which were initially transported by the river plume offshore to the continental slope and deep sea were advected and dispersed by strong coastal circulations governed by the Kuroshio Current before they reached the sea floor.

Strong wind forcing during the typhoon wind increased turbulence in the upper layer and, therefore, decreased sediment settling speed during its transport by the river plume. However, elevated wind stress resulted in high velocity of plume propagation. As a consequence, a larger fraction of sediments was transported offshore from the shallow shelf before it sank beneath the plume. These factors resulted in a lower ratio of sediment deposit volume to total sediment influx compared to freshet conditions.

Elevated sediment runoff during a typhoon event can result in submarine mudslides in the areas of active sediment loads. Based on the simulation results, we identified zones within the study area characterized by a high possibility of submarine landslide formation. In addition, we identified the potential pathways of auto-suspending gravity flows induced by the submarine landslides. The obtained results may have practical implications related to the construction of artificial structures, such as telecommunication cables and underwater pipelines, on the seafloor in the study region.

Acknowledgements. Funding of this research was provided by the Russian Scientific Foundation, research project 14-50-00095 (model development and numerical experiments), and Tainan Hydraulics Laboratory, National Cheng-Kung University, Taiwan (field work and data analyses). Authors wish to thank Aleksandr Izhitsky and Aleksandr Grabovsky for valuable support during the fieldwork, Marina Kravchishina for granulometric analysis of water samples, and many colleagues at THL for their hospitality and assistance. This article benefited from critical comments and constructive suggestions from two anonymous reviewers.

Edited by: I. Didenkulova

Reviewed by: two anonymous referees

\section{References}

Antonov, J. I., Seidov, D., Boyer, T. P., Locarnini, R. A., Mishonov, A. V., Garcia, H. E., Baranova, O. K., Zweng, M. M., and Johnson, D. R.: World Ocean Atlas 2009, Volume 2: Salinity, edited by: Levitus, S., NOAA Atlas NESDIS 69, U.S. Gov. Printing Office, Washington, D.C., 184 pp., 2010.

Blumberg, A. F. and Mellor, G. L.: A description of a threedimensional hydrodynamic model of New York harbor region, J. Hydr. Eng., 125, 799-816, 1987.

Carter, L., Milliman, J. D., Talling, P. J., Gavey, R., and Wynn, R. B.: Near-synchronous and delayed initiation of long runout submarine sediment flows from a record-breaking river 
flood, offshore Taiwan, Geophys. Res. Lett., 39, L12603, doi:10.1029/2012GL051172, 2012.

Carter, L., Gavey, R. P. Talling, and Liu, J.: Insights into submarine geohazards from breaks in subsea telecommunication cables, Oceanography, 27, 58-67, 2014.

Chang, C.-P., Yeh, T.-C., and Chen, J. M.: Effects of Terrain on the Surface Structure of Typhoons over Taiwan, Mon. Weather Rev., 121, 734-752, 1993.

Chang, M.-H., Tang, T. Y., Ho, C.-R., and Chao, S.-Y.: Kuroshioinduced wake in the lee of Green Island off Taiwan, J. Geophys. Res.-Ocean., 118, 1508-1519, 2013.

Chien, H., Chiang, W.-S., Kao, S.-J., Liu, J. T., Liu, K.-K., and Liu, P. L.-F.: Sediment dynamics observed in the Jhoushuei River and adjacent coastal zone in Taiwan Strait, Oceanography, 24, 123 131, 2011.

Dadson, S., Hovius, N., Pegg, S., Dade, W. B., Horng, M. J., and Chen, H.: Hyperpycnal river flows from an active mountain belt, 11, F04016, doi:10.1029/2004JF000244, 2005.

Flather, R. A.: A Tidal Model of the North-West European Continental Shelf, Memoires de la Societe royale des sciences de Liege, 10, 141-164, 1976.

Gilson, J. and Roemmich, D.: Mean and temporal variability of Kuroshio geostrophic transport south of Taiwan (1993-2001), J. Oceanogr., 58, 183-195, 2002.

Hale, R. P., Nittrouer, C. A., Liu, J. T., Keil, R. G., and Ogston, A. S.: Effects of a major typhoon on sediment accumulation in Fangliao Submarine Canyon, SW Taiwan, Marine Geol., 326, 116130, 2012.

Hampton, M. A., Lee, H. J., and Locat, J.: Submarine landslides, Rev. Geophys., 34, 33-59, 1996.

Hilton, R. G., Galy, A., and Hovius, N.: Riverine particulate organic carbon from an active mountain belt: importance of landslides. Global Biogeochemical Cycles, 22, GB1017, doi:10.1029/2006GB002905, 2008.

Hsin, Y.-C., Wu, C.-R., and Shaw, P.-T.: Spatial and temporal variations of the Kuroshio east of Taiwan, 19822005: A numerical study, J. Geophys. Res., 113, C04002, doi:10.1029/2007JC004485, 2008.

Hsin, Y.-C., Qiu, B., Chiang, T.-L., and Wu, C.-R.: Seasonal to interannual variations in the intensity and central position of the surface Kuroshio east of Taiwan, J. Geophys. Res., 118, 43054316, doi:10.1002/jgrc.20323, 2013.

Hsu, S.-K., Kuo, J., Lo, C.-L., Tsai, C.-H., Doo, W.-B., Ku, C.Y., and Sibuet, J.-C.. Turbidity Currents, Submarine Landslides and the 2006 Pingtung Earthquake off SW Taiwan, Terr. Atmos. Ocean Sci., 19, 767-772, 2008.

Hu, C. K., Chiu, C. T., Chen, S. H., Kuo, J. Y., Jan, S., and Tseng, Y. H.: Numerical simulation of barotropic tides around Taiwan, Terr. Atmos. Ocean Sci., 21, 71-84, 2010.

Huh, C.-A., Lin, H.-L., Lin, S., and Huang, Y.-W.: Modern accumulation rates and a budget of sediment off the Gaoping (Kaoping) River, SW Taiwan: A tidal and flood dominated depositional environment around a submarine canyon, J. Marine Syst., 76, 405416, 2009.

Hunter, J. R., Craig, P. D., and Phillips, H. E.. On the use of random walk models with spatially variable diffusivity, J. Comp. Phys., 106, 366-376, 1993.
Hwang, C.: Suspended sediments of Taiwan rivers and their geomorphological significance, Bulletin of Nation Taiwan Normal University, 27, 649-677, 1982.

James, I. D.: Modelling pollution dispersion, the ecosystem and water quality in coastal waters: a review, Environ. Model. Softw., 17, 363-385, 2002.

Jan, S., Wang, J., Yang, Y. J., Hung, C. C., Chern, C. S., Gawarkiewicz, G., Lien, R.-C., Centurioni, L., Kuo, J.-U., and Wang, B.: Observations of a freshwater pulse induced by Typhoon Morakot off the northern coast of Taiwan in August 2009, J. Marine Res., 71, 19-46, 2013.

Jia, Y. and Liu, Q.: Eddy shedding from the Kuroshio bend at Luzon Strait, J. Oceanogr., 60, 1063-1069, 2004.

Jiang, W.-T., Chen, J.-C., Huang, B.-J., Chen, C.-J., Lee, Y.-T., Huang, P.-R., Lung, C.-C., and Huang, S.-W.: Mineralogy and physical properties of cored sediments from the gas hydrate potential area of offshore southwestern Taiwan, Terr. Atmos. Ocean. Sci., 17, 981-1007, 2006.

Johns, W. E., Lee, T. N., Zhang, D., Zantopp, R., Liu, C.-T., and Yang, Y.: The Kuroshio East of Taiwan: Moored Transport Observations from the WOCE PCM-1 Array, J. Phys. Oceanogr., 31, 1031-1053, 2001

Kao S.-J. and Liu, K.-K.: Particulate organic carbon export from a subtropical mountainous river (Lanyang-His) in Taiwan, Limnol. Oceanogr., 41, 1749-1757, 1996.

Kao, S.-J., Chan, S. C., Kuo, C. H., and Liu, K. K.: Transportdominated sediment loading in Taiwanese rivers: a case study from the Ma-an Stream, J. Geol., 113, 217-225, 2005.

Kao, S.- J., Jan, S., Hsu, S.-C., Lee, T.-Y., and Dai, M.: Sediment budget in the Taiwan Strait with high fluvial sediment inputs from mountainous rivers: New observations and synthesis, Terr. Atmos. Ocean. Sci., 19, 525-546, 2008.

Korotenko, K. A., Osadchiev, A. A., Zavialov, P. O., Kao, R.-C., and Ding, C.-F.: Effects of bottom topography on dynamics of river discharges in tidal regions: case study of twin plumes in Taiwan Strait, Ocean Sci., 10, 863-879, doi:10.5194/os-10-8632014, 2014.

Lamb, M. P. and Mohrig, D.: Do hyperpycnal-flow deposits record river-flood dynamics?, Geology, 37, 1067-1070, 2009.

Large, W. G., McWilliams, J. C., and Doney, S. C.: Oceanic vertical mixing: a review and a model with a nonlocal boundary layer parameterization, Rev. Geophys., 32, 363-403, 1994.

Liang, W.-D., Tang, T. Y., Yang, Y. J., Ko, M. T., and Chuang, W.S.: Upper-ocean currents around Taiwan, Deep Sea Res. II, 50, 1085-1105, 2003.

Liu, J. T., Lin, H.-L., and Huang, J. J.: A submarine canyon conduit under typhoon conditions off Southern Taiwan. Deep-Sea Res. I, 53, 223-240, 2006.

Liu, J. P., Liu, C. S., Xu, K. H., Milliman, J. D., Chiu, J. K., Kao, S. J., and Li, S. W.: Flux and fate of small mountainous rivers derived sediments into the Taiwan Strait, J. Geol., 256, 65-76, 2008.

Liu, C.-C., Chiu Y.-F., Lee J.-F., Su C.-H., Chen M.-T., Lee C.-T., Tu L.-F., and Cheng P.-C.: Enhancement of marine meteorology simulation technology on coastal and harbor areas (1/2), Institute of Harbor \& Marine Technology Center, Ministry of Transportation and Communication, Taichung City, Taiwan (R.O.C.), ISBN978-986-04-0453-1, 2014. 
Meiburg, E. and Kneller, B.: Turbidity currents and their deposits, Ann. Rev. Fluid Mech., 42, 135-156, 2010.

Mellor, G. L. and Yamada, T.: Development of a turbulent closure model for geophysical fluid problems, Rev. Geophys. Space Phys., 20, 851-875, 1982.

Milliman, J. D. and Kao, S.-J.: Hyperpycnal discharge of fluvial sediment to the ocean: Impact of super-typhoon Herb (1996) on Taiwanese rivers, J. Geol., 113, 503-516, 2005.

Milliman, J. D. and Syvitski, J. P. M.: Geomorphic/tectonic control of sediment discharge to the ocean: the importance of small mountainous rivers, J. Geol., 100, 525-544, 1992.

Milliman, J. D., Lin, S. W., Kao, S. J., Liu, J. P., Liu, C. S., Chiu, J. K., Lin, Y. C.: Short-term changes in seafloor character due to flood-derived hyperpycnal discharge: typhoon Mindulle, Taiwan, July 2004. Geology, 35, 779-782, 2007.

Mirabito, C., Haley Jr., P., Lermusiaux, P. F. J., and Leslie, W. G.: A River Discharge Model for Coastal Taiwan during Typhoon Morakot, Rep. MSEAS-13, MIT, Cambridge, MA, 2012.

Nash, D. B.: Effective sediment-transporting discharge from magnitude-frequency analysis, J. Geol., 102, 79-95, 1994.

Orton, G. J. and Reading, H. G.: Variability of deltaic processes in terms of sediment supply, with particular emphasis on grain size, Sedimentology, 40, 475-512, 1993.

Osadchiev, A. A. and Zavialov, P. O.: Lagrangian model of a surface-advected river plume, Cont. Shelf Res., 58, 96-106, 2013.

Ross, O. N. and Sharples, J.. Recipe for 1-D Lagrangian particle tracking models in space-varying diffusivity, Limnol. Oceanogr.Meth., 2, 289-302, 2004.

Rudnick, D. L., Jan, S., Centurioni, L., Lee, C. M., Lien, R.-C., Wang, J., Lee, D.-K., Tseng, R.-S., Kim, Y. Y., and Chern, C.S.: Seasonal and mesoscale variability of the Kuroshio near its origin, Oceanography, 24, 52-63, 2011.

Shen, H.-C.: Topography Induced Flow Variations between Taitung-Lutao off Southeast Taiwan. Kaoshiung, Taiwan: Institute of Applied Marine Physics and Undersea Technology, National Sun Yat-sen University, Master's thesis, 138 pp., 2012.

Sibuet, J. C., Hsu, S. K., and Normand, A.: Tectonic significance of the Taitung Canyon, Huatung Basin, east of Taiwan, Mar. Geophys. Res., 25, 95-107, 2004.

Smagorinsky, J.: General circulation experiments with the primitive equation. 1. The basic experiment, Mon. Weather Rev., 91, 99$165,1963$.
Stokes, G. G.. On the effect of the internal friction of fluids on the motion of pendulums, Cambridge Philosophical Transactions, 9, 8-106, 1851.

Su, C.-C., Tseng, J.-Y., Hsu, H.-H., Chiang, C.-S., Yu, H.-S., Lin, S., and Liu, J. T.. Records of submarine natural hazards off SW Taiwan. Geological Society, London, Special Publications, 361, 41-60, 2012.

Syvitski, J. P. M. and Saito, Y.: Morphodynamics of Deltas Under the Influence of Humans, Global Planet. Change, 57, 261-282, 2007.

Visser, A. W.: Using random walk models to simulate the vertical distribution of particles in a turbulent water column, Marine Ecol. Prog. Ser., 158, 275-281, 1997.

Walsh, J. P. and Nittrouer, C. A.: Understanding fine-grained riversediment dispersal on continental margins, Marine Geol., 263, 34-45, 2009.

Warrick, J. A.: Eel River margin source-to-sink sediment budgets: Revisited, Marine Geol., 351, 25-37, 2014.

Warrick, J. A. and Milliman, J. D.: Hyperpycnal sediment discharge from semiarid southern California rivers: implications for coastal sediment budgets, Geology, 31, 781-784, 2003.

Wu, L., Liang, J., and Wu, C.-C.: Monsoonal influence on Typhoon Morakot (2009) - Part I: Observational Analysis, J. Atmos. Sci., 68, 2208-2220, 2011.

Wyrtky, K.: Scientific results of marine investigations of the South China Sea and the Gulf of Thailand, In NAGA Report, Vol. 2, The University of California, Scripps Institution of Oceanography, La Jolla, USA, 164-169, 1961.

Yu, H. S.: Hyperpycnal discharge of fluvial sediment to the ocean: impact of supertyphoon herb (1996) on Taiwanese rivers: a discussion, J. Geol., 114, 763-765, 2006.

Yuan, Y., Liu, C., Pan, Z., and Zheng, S.: Circulation east of Taiwan and in the East China Sea and east of Ryukyu Islands during early summer 1985, Acta Oceanol. Sin., 15, 423-435, 1996.

Yuan, Y., Liu, Y., Liu, C., and Su, J.: The Kuroshio east of Taiwan and the currents east of the Ryukyu Islands during October of 1995, Acta Oceanol. Sin., 17, 1-13, 1998.

Zu, T., Gan, J., and Erofeeva, S. Y.: Numerical study of the tide and tidal dynamics in the South China Sea, Deep-Sea Res. I, 55, 137-154, 2008. 